\title{
Poly (Methyl Methacrylate)-SiC Nanocomposites Prepared Through in Situ Polymerization
}

\author{
Flávio James Tommasini ${ }^{a}{ }^{\circledR}$, Leonardo da Cunha Ferreira ${ }^{b}$, Lucas Galhardo Pimenta Tienne ${ }^{b}$ \\ Vínícius de Oliveira Aguiar ${ }^{b}$, Marcelo Henrique Prado da Silva $^{a}$, Luiz Felipe da Mota Rocha ${ }^{b}$, \\ Maria de Fátima Vieira Marques ${ }^{b}$ \\ ${ }^{a}$ Instituto Militar de Engenharia (IME), Seção de Engenharia de Materiais, Praça General Tibúrcio, 80- \\ Praia Vermelha, Urca, CEP 22290-270, Rio de Janeiro, RJ, Brasil \\ ${ }^{b}$ Instituto de Macromoléculas Professora Eloisa Mano (IMA), Universidade Federal do Rio de Janeiro \\ (UFRJ), Cidade Universitária - Centro de Tecnologia/Bloco J, CEP 21941-598, Rio de Janeiro, RJ, \\ Brasil
}

Received: February 04, 2018; Revised: May 27, 2018; Accepted: August 05, 2018

In this study, polymeric nanocomposites based on poly(methyl methacrylate) (PMMA) and silicon carbide $(\mathrm{SiC})$ nanoparticles were prepared by radical mass polymerization in the presence of filler. Nanoparticles of $\mathrm{SiC}$ with and without surface treatment with organosilane were obtained .The nanocomposites were characterized by X-ray fluorescence (XRF), infrared spectroscopy (FTIR), thermogravimetry (TGA) and Field Emission Gun Scanning Electron Microscopy (FEG SEM) with an energy dispersive $\mathrm{x}$-ray spectroscopy (EDS) detector. The produced nanocomposites showed welldispersed $\mathrm{SiC}$ incorporation in the PMMA matrix. The results pointed that the surface treatment on $\mathrm{SiC}$ fillers was successful on enhancing the interaction between the organic matrix and the inorganic filler.

Keywords: poly(methyl methacrylate), SiC nanoparticles, nanocomposites, in situ polymerization.

\section{Introduction}

The production of novel polymeric nanocomposites have been widely studied by the current applications on nanosized inorganic fillers in the food packaging field, barrier applications, sensors, antimicrobial, conductive, coatings, antiballistic products and other materials ${ }^{1-4}$. The new generation of these polymer nanocomposites contains nitrides ( $\mathrm{TiN}, \mathrm{CrN}, \mathrm{ZrN}, \mathrm{BN}$ ), carbides (WC, $\mathrm{SiC}, \mathrm{B}_{4} \mathrm{C}$ ), borides $\left(\mathrm{WB}, \mathrm{ZrB}_{2}, \mathrm{TiB}_{2}, \mathrm{CrB}_{2}\right)$, metal oxides $\left(\mathrm{Al}_{2} \mathrm{O}_{3}, \mathrm{Fe}_{3} \mathrm{O}_{2}\right.$, $\mathrm{MgO}, \mathrm{CeO}_{2}, \mathrm{TiO}_{2}, \mathrm{Y}_{2} \mathrm{O}_{3}, \mathrm{SiO}_{2}, \mathrm{ZrO}_{2}$ ), carbon nanotubes, cellulose nanofibrils, and other kind of nanoparticles as disperse phase ${ }^{5-7}$. The characteristics and properties of the nanocomposites are influenced by the type of filler used as well as by the polymeric matrix. The applications encompass several areas such as electronic, medicine, military, aerospace, marine and vehicles ${ }^{8,9}$.

Many methods are used to the production of polymeric nanocomposite materials, such as ex or in situ polymerization, extrusion molding, injection molding, plasma coating, ball milling and other processes. Particularly, the in situ polymerization enables an effective and homogeneous filler dispersion into the organic matrix ${ }^{10,11}$. Poly(methyl methacrylate) (PMMA) is well-known as a polymer used in the production of materials with low cost, but still with great properties, as well as transparency, thermal stability, electrical insulation and mechanical resistance ${ }^{12}$. In recent study, Shokr (2017)

*e-mail: fallmasini@ima.ufrj.br reported flexible optoelectronic applications and evaluated the optical properties of nanocomposite films with poly (methyl methacrylate) matrices based on the incorporation of Eosin via the spin coating technique. According to the author, the developed nanocomposite may be useful as photoconductive flexible optical devices ${ }^{13}$.

Junior and collaborators (2014) produced PMMA matrices with incorporated PMMA/silica and PMMA/silica-graftedPMMA nanocomposites functionalized via atom transfer radical polymerization to achieve a uniform dispersion into the polymer matrix. The results indicated the potential of friction spot welding as alternative fabrication technology for joining nanocomposite engineering structures ${ }^{14}$.

Consequently, several fillers can be used to be incorporated into polymer-based nanocomposites. Silicon carbide ( $\mathrm{SiC})$ is one of the main filler for advanced high power and high temperature electronic applications ${ }^{15,16}$. Silicon carbide has innovated in the development of structural ceramics with high performance in the production of materials that request a low coefficient of thermal expansion and high thermal conduction characteristics ${ }^{17}$.

In this work, poly (methyl methacrylate) nanocomposites containing silicon carbide nanofillers (untreated or treated with a silane surface compatibilizing) were investigated and characterized to be used to production of innovative products which can be films, covers and materials with better optical properties. Therefore, produced nanocomposites may allow the production of materials holding highlights new properties. 


\section{Materials and Methods}

\subsection{Materials}

Methyl methacrylate (MMA) monomer obtained from Vetec, located in Rio de Janeiro - RJ/Brasil, was distilled under the presence of hydroquinone supplied by SigmaAldrich with simple distillation equipment. Nanoparticles of silicon carbide $(\beta-\mathrm{SiC})>$ with $>99 \%$ purity, size distribution of particles $50-40 \mathrm{~nm}$ and $3.21 \mathrm{~g} / \mathrm{cm}^{3}$ density were obtained from Sky Spring Nanomaterials, Inc. The benzoyl peroxide initiator used as initiator of the bulk polymerization was acquired from Sigma-Aldrich, located in Jurubatuba, São Paulo - SP/Brazil. The surface compatibilization of the $\mathrm{SiC}$ nanoparticles was fulfilled with $20 \mathrm{~mL}$ of dry toluene and $0.2005 \mathrm{~g}(5 \mathrm{mmol})$ of $\mathrm{SiC}$ were added to a $50 \mathrm{~mL}$ flask. Then, $1.07 \mathrm{~mL}$ (1.03761 g) of trimethoxy vinyl silane 98\% (Sigma-Aldrich, located in Jurubatuba, São Paulo - SP/Brazil) were added to the reaction. The flask was heated up to $90^{\circ} \mathrm{C}$ under constant stirring, during 5 hours. Finally, the SiC fillers have been filtered and dried in an oven at $40^{\circ}$ for 2 hours.

\subsection{Syntheses of the untreated and treated nanocomposites}

In situ bulk polymerization was carried out constant magnetic stirring, with $20 \mathrm{~mL}$ of distilled methyl methacrylate monomer, $0.20 \mathrm{~g}$ of benzoyl peroxide and different $\mathrm{SiC}$ proportions added into the Erlenmeyer flask. The polymerization temperature was about of $80-90^{\circ} \mathrm{C}$, constant stirring to avoid bubbles into the nanomaterials and it assures good reaction coefficient. In order to the apparent viscosity increased into reaction system, the materials were transferred to a kiln at about 40 ${ }^{\circ} \mathrm{C}$ by period 24 hours, to the complete polymerization of all PMMA nanocomposites (U-PMMA/SiC and T-PMMA/ $\mathrm{SiC}$ ) respectively. According to Figure 1, SiC surface was modificated with trimethoxy vinyl silane (TVS) to avoid the agglomeration of the SiC particles into the matrix of

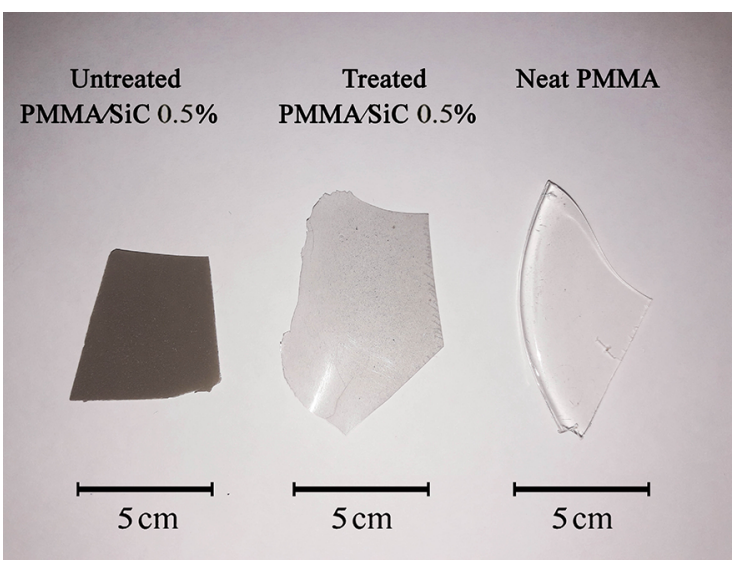

Figure 1. Photography of the untreated PMMA/SiC $0.5 \%$ nanocomposite and treated $\mathrm{PMMA} / \mathrm{SiC} 0.5 \%$ nanocomposite samples.
PMMA material, which can promote an efficient coupling to hydrocarbon matrix.

\subsection{Characterization}

Chemical composition of both untreated and treated nanocomposites was evaluated using X-ray fluorescence spectroscopy (XRF) by use of a Rigaku RIX 3100 spectrometer. The Silicon content was determined and expressed in terms of percentage, and the presence of the silicon carbide into the polymer matrix was confirmed.

Fourier transform infrared spectroscopy (FTIR) was performed with a Varian Excalibur FT-IR spectrometer, using a $\mathrm{KBr}$ pellet. The spectra were obtained from 500 to $4000 \mathrm{~cm}^{-1}$ with 50 scans and $2 \mathrm{~cm}^{-1}$ of resolution.

The thermal stability of the materials were analysed by thermogravimetric analysis (TGA) in order to determinate the onset degradation temperature $\left(\mathrm{T}_{\text {onset }}\right)$, maximum degradation temperature $\left(\mathrm{T}_{\max }\right)$ and final degradation temperature, $\left(\mathrm{T}_{\text {end }}\right)$ of the nanocomposite samples. PMMA and all nanocomposites were analysed. The test was conducted from 30 to $700^{\circ} \mathrm{C}$, at $10^{\circ} \mathrm{C} \mathrm{min}^{-1}$, under nitrogen atmosphere. The samples were weighed to $6-7 \mathrm{mg}$.

The morphology, dispersion of particles and interface structure of the nanocomposites were observed in a field emission gun scanning electron microscope (FEG-SEM), model FEG QUANTA 250 (FEI) under high vacuum and high voltage $(\mathrm{HV})$ of $30 \mathrm{kV}$ to silicon carbide particles, while 2-3 kV (untreated and treated) to all nanocomposites, respectively. The sample surfaces were cryo-sectioned in liquid nitrogen and coated with a thin platinum layer in order to provide conductivity.

\section{Results and Discussions}

X-ray fluorescence data are reported in the Table 1, and presents the percentages of elemental silicon in the produced nanocomposites. According to results, Si incorporation was more evident with increasing SiC nanofillers amount in the mass polymerization of the PMMA matrix. Both nanocomposites showed the presence of silicon in the matrix, which suggests the effective incorporation of the fillers into the matrix. The higher amount of silicon in the untreated nanocomposites compared to treated nanocomposites can indicate a better dispersion of $\mathrm{SiC}$ fillers into the matrix, which corroborate with lower 1 transparency of the untreated nanocomposites when compared to the treated nanocomposites.

According to the FTIR analysis spectra results, the incorporation of the $\mathrm{SiC}$ filler into the PMMA matrix was obtained for all nanocomposites during polymerization process, which can be observed by presence of absorption bands related to silicon carbide and PMMA polymer (Figure 2)

According to the literature, absorption bands at 994-703 $\mathrm{cm}^{-1}$ and $1240-1247 \mathrm{~cm}^{-1}$, can be attributed to stretching vibrations of $\mathrm{Si}-\mathrm{C}(\mathrm{vSi}-\mathrm{C})$ and to the bending vibration of 
Table 1. Percentages of silicon chemical composition of the U-PMMA $\mathrm{SiC}$ and T-PMMA $\backslash \mathrm{SiC}$ nanocomposites by X-ray fluorescence.

\begin{tabular}{lccc}
\hline PMMA & \multicolumn{3}{c}{ \% Silicon (m/m) } \\
\hline $\begin{array}{l}\text { U-PMMA/SiC } \\
\text { Nanocomposites }\end{array}$ & $\begin{array}{c}\text { \% } \\
\text { Silicon } \\
(\mathbf{m} / \mathbf{m})\end{array}$ & $\begin{array}{c}\text { T-PMMA/SiC } \\
\text { Nanocomposites } \\
\mathbf{( \% )}\end{array}$ & $\begin{array}{c}\% \\
\text { Silicon } \\
(\mathbf{m} / \mathbf{m})\end{array}$ \\
\hline U-PMMA/SiC 0.1 & 30 & T-PMMA/SiC 0.1 & 24 \\
U-PMMA/SiC & 75 & T-PMMA/SiC 0.25 & 40 \\
0.25 & 67 & T-PMMA/SiC 0.5 & 22 \\
U-PMMA/SiC 0.5 & 81 & T-PMMA/SiC 1 & 66 \\
\hline U-PMMA/SiC 1 & & &
\end{tabular}

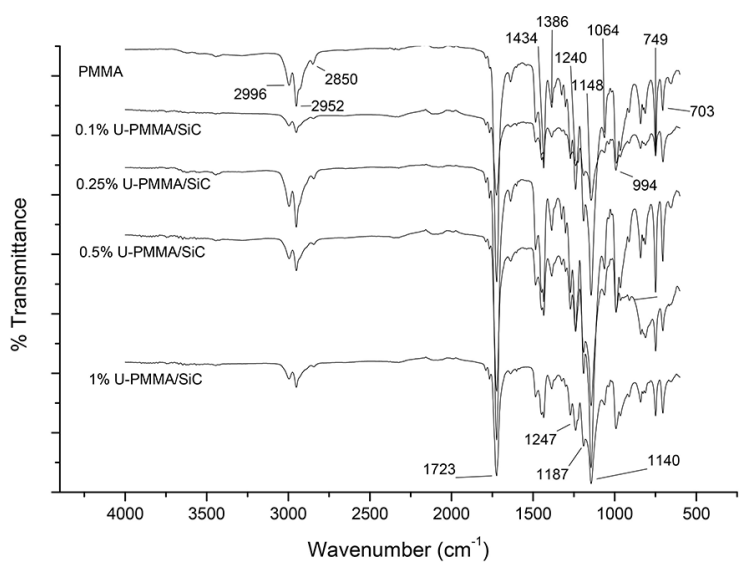

Figure 2. FTIR spectra of the neat PMMA polymer and nanocomposite samples, $0.1,0.25,0.5$ and $1 \%$ of untreated $\mathrm{SiC}$ fillers.

Si-C $(\delta \mathrm{Si}-\mathrm{C})$, respectively ${ }^{18}$; in the spectra of the obtained nanocomposite, these absorptions are coupled with PMMA vibrational modes. All nanocomposites (U-PMMA/SiC and T-PMMA/ SiC) presented intense absorption bands at 1724 $\mathrm{cm}^{-1}$, which were associated to stretching of carbonyl group $(\mathrm{C}=\mathrm{O})$, belonging to the PMMA polymer.

Other absorption bands were observed at 2996-2952 $\mathrm{cm}^{-1}\left(-\mathrm{CH}_{3}\right.$ and $-\mathrm{CH}_{2}$ stretching, respectively), $1434 \mathrm{~cm}^{-1}(-$ $\mathrm{CH}_{2}$; bending vibration), $1064 \mathrm{~cm}^{-1}$ (C-O; bond stretching), $1386-749 \mathrm{~cm}^{-1}$ ( $\alpha$-methyl group vibrations), as well as PMMA absorption bands at 1194-1146 $\mathrm{cm}^{-1}$, and shifting of oxygen bonded to $\mathrm{CH}_{3}$ (ether group $\left.\mathrm{O}-\mathrm{CH}_{3}\right)^{19-21}$. Figure 3 shows the spectra of the treated nanocomposites with organo modifier; according to the literature the peaks at $1089 \mathrm{~cm}^{-1}$ and 1385 $\mathrm{cm}^{-1}$, can be associated to Si-O stretching vibrations and $\mathrm{O}-\mathrm{H}$ group vibrations. this technique indicates that a very small amount of the organo compound was incorporated to the surface of the silicon carbide because it is not possible to observe the characteristic absorptions of the compound when comparing the spectra of the treated and untreated nanocomposites.

Thermogravimetry results corroborated FTIR analyses, which demonstrated the successful synthesis of the neat polymer and the difference between the treated and untreated $\mathrm{SiC}$ nanocomposites. According to Figure 4, all produced materials showed DTG curves with three degradation steps,

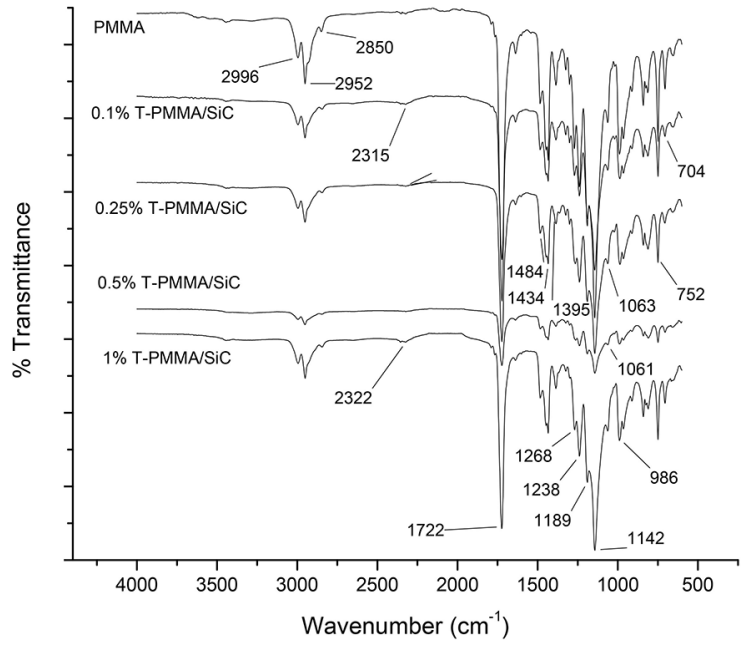

Figure 3. FTIR spectra of the nanocomposite samples, 0.1, 0.25, 0.5 and $1 \%$ of treated $\mathrm{SiC}$ fillers, respectively.

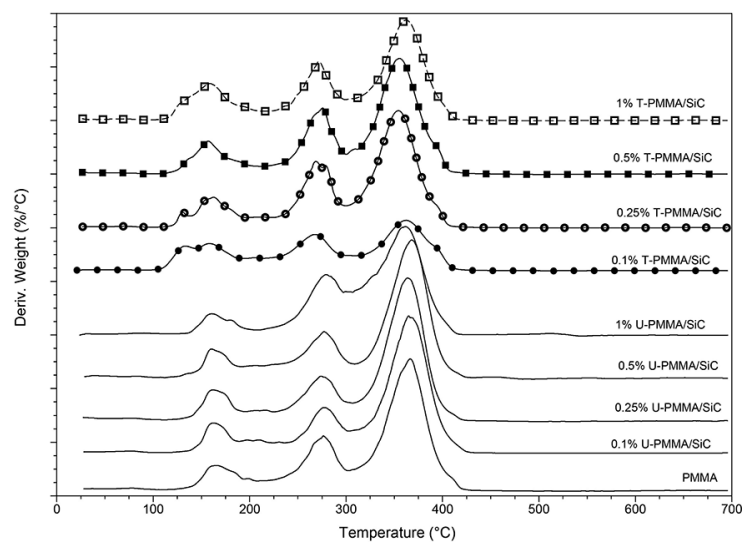

Figure 4. Overlay of the DTG curves of the Neat PMMA, untreated PMMA/SiC (U-PMMA/SiC) nanocomposites and treated PMMA/ $\mathrm{SiC}(\mathrm{T}-\mathrm{PMMA} / \mathrm{SiC})$ nanocomposites with vinyl trimethoxy silane.

which correspond to PMMA degradation stages produced via radical mechanism ${ }^{22,23}$. The maximum temperature $\left(\mathrm{T}_{\max }\right)$ on the first degradation stage was indicated at approximately $159^{\circ} \mathrm{C}$, and it can be described as mass loss reached during the scission of unsaturated chain ends, while the second step showed $\mathrm{T}_{\text {max }}$ at approximately $275^{\circ} \mathrm{C}$, achieved due to the disruption of weak head-to-head linkages. Therefore, the third stage of degradation showed $\mathrm{T}_{\max }$ and $\mathrm{T}_{\text {end }}$ at approximately $366-404^{\circ} \mathrm{C}$, respectively, which correspond to breakage of the PMMA random chains ${ }^{24}$. However, treated nanocomposites presented a fourth stage of degradation, which can suggest some interface interaction during the bulk polymerization between the treated $\mathrm{SiC}$ fillers and PMMA polymer chains. Fourth stage had the $\mathrm{T}_{\text {onset }}$ displaced to lower temperatures, 112 and $123^{\circ} \mathrm{C}$, respectively, while $\mathrm{T}_{\text {max }}$ was indicated at approximately $130-132^{\circ} \mathrm{C}$. In general, the incorporation effect of $\mathrm{SiC}$ fillers (treated and untreated) provided higher thermal stability than neat PMMA polymer, as observed by the displacement of the derivative thermogravimetry curves of the 
nanocomposites to higher temperatures, while an interaction between the treated $\mathrm{SiC}$ filler interface and PMMA polymer can be suggested, as shown in Figure 4. Surface interaction of treated fillers with the PMMA polymer can suggest a relation with the transparency effect of polymeric films.

According to results of the Table 2, treated nanocomposites showed higher thermal stabilities, when compared to untreated ones, which suggest the efficiency of the filler treatment with silane and effective linkage between surface fillers with the PMMA chains.

According to observation of the FEG-SEM images was possible to determine the high proportion of $\mathrm{SiC}$ particles with nanometric dimensions, as shown in Figure 5.

FEG-SEM analysis allowed the observation of different morphologies to both untreated and treated $\mathrm{SiC}$ nanoparticles disperse into the PMMA matrix. However, it was possible to distinguish untreated $\mathrm{SiC}$ agglomerated with circle forms inside the polymeric matrix, whereas the treated $\mathrm{SiC}$ nanoparticles remained more dispersed by PMMA polymer. This effect can corroborate with the opacity of the untreated nanocomposites and translucency of the treated nanocomposites with vinyl trimethoxy silane, which they conserved some transparency characteristic of the neat PMMA matrix (Figure 6).

This effect suggested efficiency in the synthesis procedures and filler modification and good dispersion of the $\mathrm{SiC}$ nanoparticles into the polymer matrix. Interface adhesions between $\mathrm{SiC}$ nanoparticles and organic matrix were visualized on both untreated and treated nanocomposites. The $\mathrm{SiC}$ incorporation into the PMMA matrix was evaluated and confirmed by energy dispersive X-ray spectroscopy (EDS) analysis. Platinum was observed in spectra of the polymer, $\mathrm{SiC}$ nanoparticles and nanocomposites due to the overcoating to avoid the degradation of the polymeric matrix and supply a better resolution to the images of all materials.According to energy dispersive X-ray spectroscopy (EDS) analyses, spectra of the nanocomposites confirmed the presence of silicon, carbon and oxygen, confirming the XRF analysis results (Figure 7).

Table 2. Thermogravimetry analysis of the PMMA polymer and synthesized nanocomposites treated and untreated with vinyl trimethoxy silane

\begin{tabular}{lcccccccc}
\hline PMMA/SiC $(\%)$ & $\mathrm{T}_{\text {lonset }}\left({ }^{\circ} \mathrm{C}\right)$ & $\mathrm{T}_{1 \text { max }}\left({ }^{\circ} \mathrm{C}\right)$ & $\mathrm{T}_{\text {2onset }}\left({ }^{\circ} \mathrm{C}\right)$ & $\mathrm{T}_{2 \max }\left({ }^{\circ} \mathrm{C}\right)$ & $\mathrm{T}_{\text {3onset }}\left({ }^{\circ} \mathrm{C}\right)$ & $\mathrm{T}_{3 \max }\left({ }^{\circ} \mathrm{C}\right)$ & $\mathrm{T}_{\text {end }}\left({ }^{\circ} \mathrm{C}\right)$ & Residue $(\%)$ \\
\hline Neat PMMA & 145 & 161 & 261 & 277 & 336 & 358 & 404 & 0.3 \\
U-PMMA/SiC 0.1 & 125 & 158 & 248 & 268 & 341 & 362 & 407 & 1 \\
U-PMMA/SiC 0.25 & 145 & 164 & 256 & 270 & 335 & 355 & 404 & 2 \\
U-PMMA/SiC 0.5 & 140 & 157 & 257 & 276 & 335 & 353 & 412 & 5 \\
U-PMMA/SiC 1 & 135 & 158 & 257 & 274 & 341 & 362 & 406 & 2 \\
T-PMMA/SiC 0.1 & 112 & $130-163$ & 263 & 276 & 345 & 365 & 421 & 35.15 \\
T-PMMA/SiC 0.25 & 123 & $132-165$ & 257 & 274 & 343 & 364 & 410 & 1 \\
T-PMMA/SiC 0.5 & 152 & 160 & 263 & 277 & 345 & 368 & 423 & 3 \\
T-PMMA/SiC 1 & 152 & 161 & 257 & 279 & 339 & 362 & 413 & 7 \\
\hline
\end{tabular}

$\mathrm{T}_{1}$ - degradation temperature of the first stage

$\mathrm{T}_{2}$ - degradation temperature of the second stage

$\mathrm{T}_{3}$ - degradation temperature of the third stage
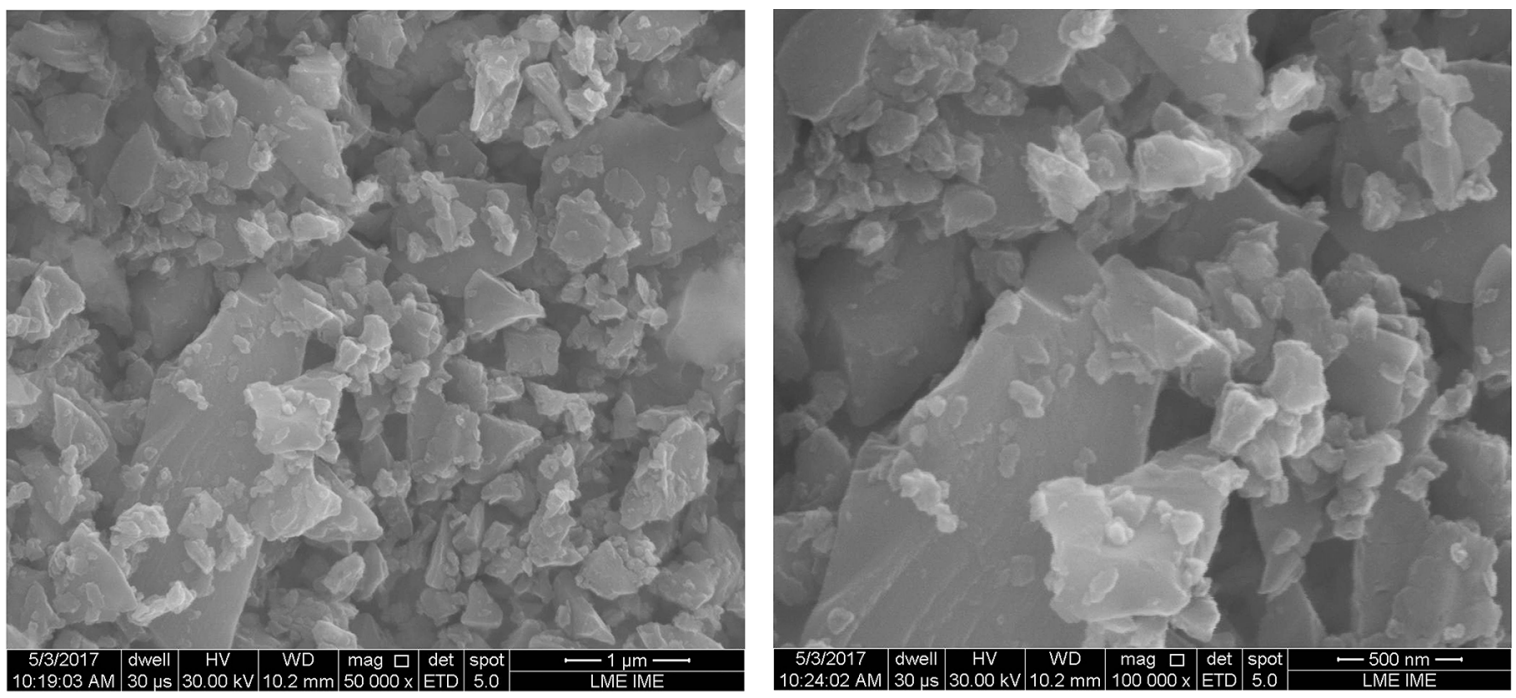

Figure 5. FEG-SEM images of the SiC particles, (5a) SiC particle images with $1 \mu \mathrm{m}$ and (5b) SiC particle images with 500nm scale bar. 

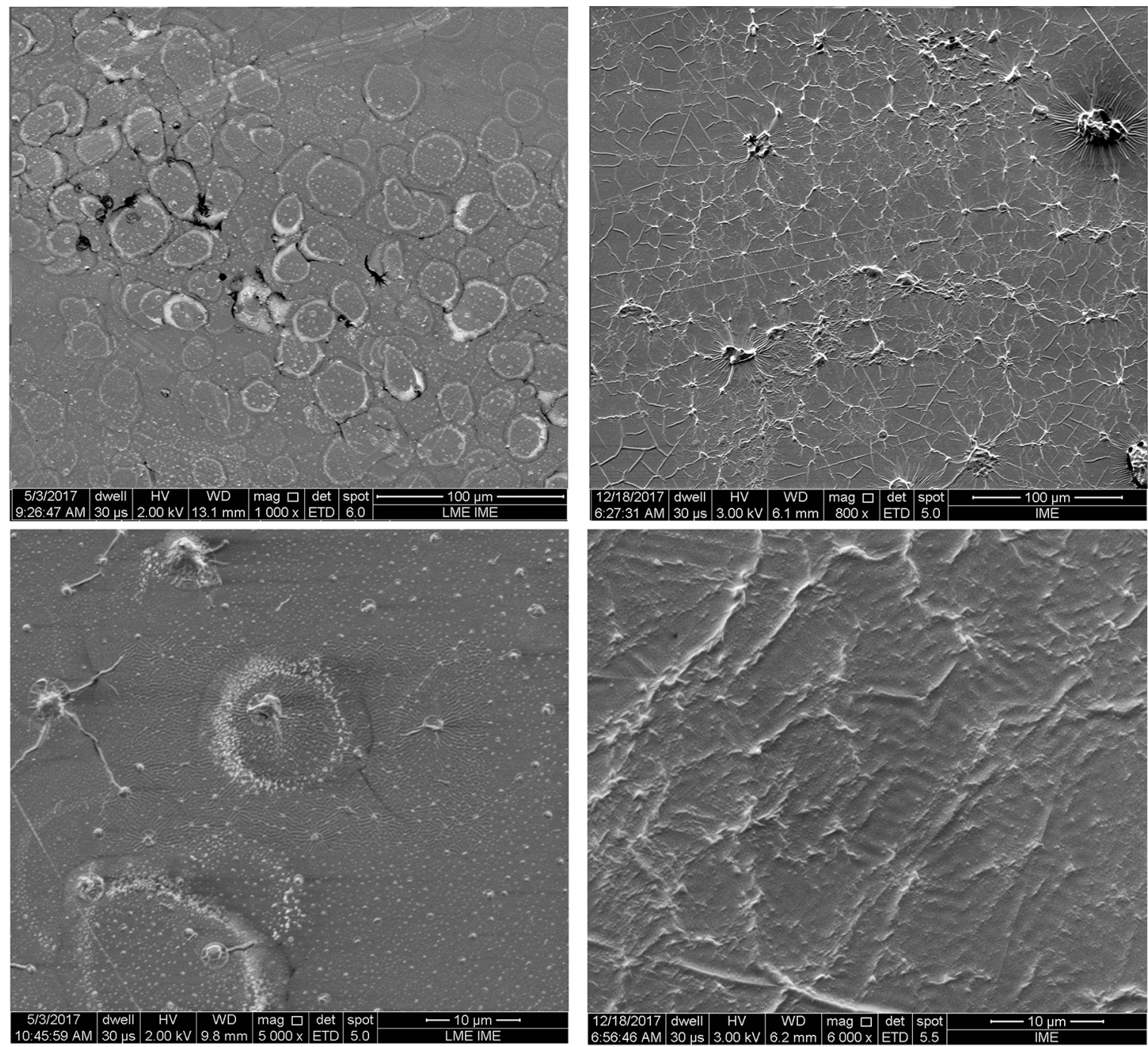

Figure 6. FEG-SEM images of the untreated and treated nanocomposites cryo-sectioned : (6a) agglomerated particles of the untreated PMMA/SiC 1\%nanocomposites, scale $100 \mu \mathrm{m} ;(6 \mathrm{~b})$ disperse particles present into the treated PMMA/SiC $1 \%$ nanocomposites, scale $100 \mu \mathrm{m}$; (6c) Micrometric agglomerated of untreated particles of the PMMA/SiC $0.5 \%$ nanocomposites, scale $10 \mu \mathrm{m}$ and (6d) good dispersion of treated particles into the PMMA/SiC $0.5 \%$ nanocomposites, scale $10 \mu \mathrm{m}$.
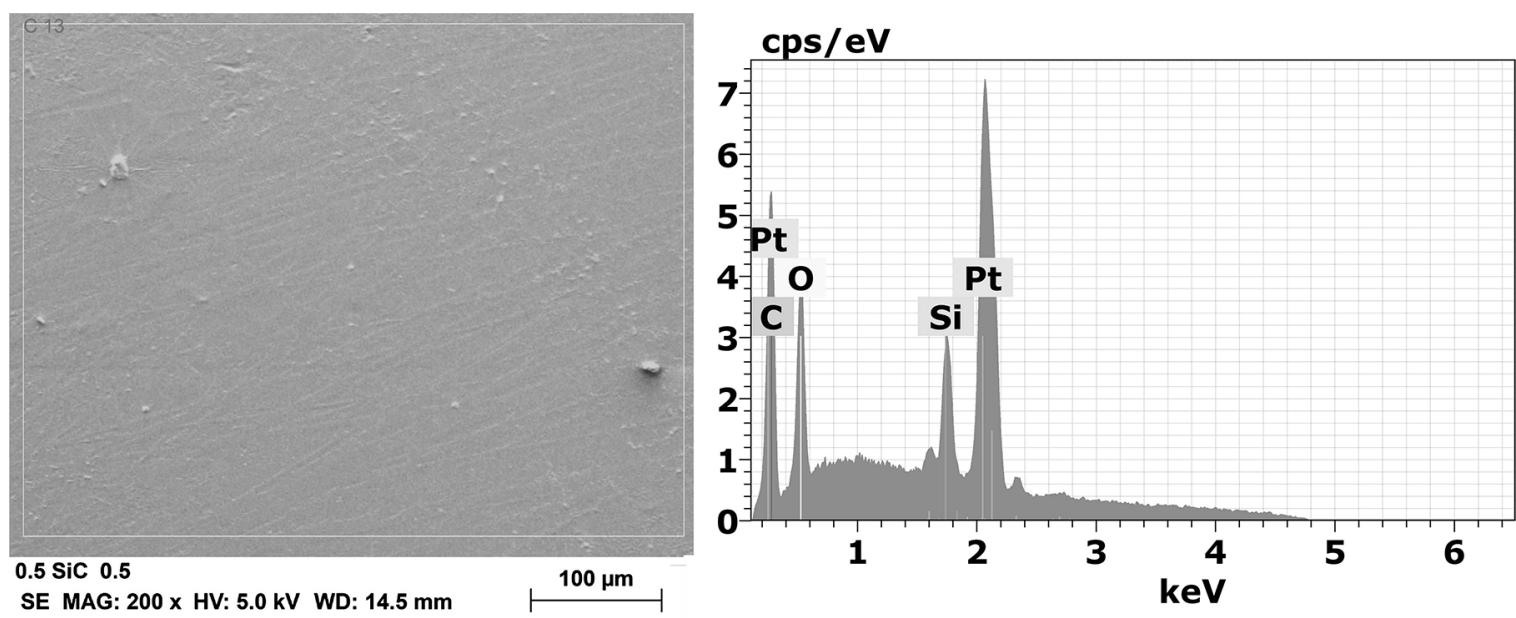

Figure 7. SEM image of the PMMA matrix containing $0.5 \%$ treated $\mathrm{SiC}$ amount and confirmed by spectrum of the energy dispersive $\mathrm{X}$-ray spectroscopy (EDS) analysis. 


\section{Conclusions}

In this study, the efficiency of surface treatment with vinyl trimethoxysilane from incorporation by the PMMA matrix was confirmed. XRF results showed the filler presence of $\mathrm{SiC}$ into the nanocomposites produced by in situ polymerization of the PMMA polymer. Therefore, FTIR analysis showed the characteristic absorption bands of the PMMA, SiC into the treated nanocomposites, what corroborate with the XRF analysis, good filler modification and transparent characteristic of the treated materials. In general, TGA analysis showed that the filler incorporation into the PMMA matrix increased the thermal stability of the nanocomposites.

Higher degradation temperatures were observed for the treated nanocomposites, when compared to untreated ones. FEG-SEM analysis showed the untreated and treated nanoparticles embedded into the PMMA matrix, which is an evidence of the PMMA polymerization success with the incorporation of $\mathrm{SiC}$ nanoparticles. Consequently, the best dispersion of the treated SiC nanoparticles corroborated with the FTIR and TGA analyses, which demonstrated a better interaction between inorganic particles and organic matrix for these samples. EDS spectra of all materials confirmed the composition obtained by XRF analyses.

\section{Acknowledgements}

The authors thank the support to this investigation by the Brazilian agencies: CNPq and CAPES.

\section{References}

1. Ávila AF, Silva Neto A, Nascimento Junior H. Hybrid nanocomposites for mid-range ballistic protection. International Journal of Impact Engineering. 2011;38(8-9):669-676.

2. Huang C, Cheng Q. Learning from nacre: Constructing polymer nanocomposites. Composites Science and Technology. 2017;150:141-166.

3. Yanik MO, Yigit EA, Akansu YE, Sahmetlioglu E. Magnetic conductive polymer-graphene nanocomposites based supercapacitors for energy storage. Energy. 2017;138:883-889.

4. Tamayo L, Azócar M, Kogan M, Riveros A, Páez M. Copperpolymer nanocomposites: An excellent and cost-effective biocide for use on antibacterial surfaces. Materials Science and Engineering: C. 2016;69:1391-1409.

5. Dufresne A. Cellulose nanomaterial reinforced polymer nanocomposites. Current Opinion in Colloid \& Interface Science. 2017;29:1-8.

6. Camargo PHC, Satyanarayana KG, Wypych F. Nanocomposites: synthesis, structure, properties and new application opportunities. Materials Research. 2009;12(1):1-39.

7. Roy M. Nanocomposite films for wear resistance applications. In: Roy M, ed. Surface Engineering for Enhanced Performance against Wear. Wien: Springer Verlag; 2013. p. 45-78.
8. Choudhary S. Dielectric dispersion and relaxations in (PVAPEO)-ZnO polymer nanocomposites. Physica B: Condensed Matter. 2017;522:48-56.

9. Zare Y, Fasihi M, Rhee KY. Efficiency of stress transfer between polymer matrix and nanoplatelets in clay/polymer nanocomposites. Applied Clay Science. 2017;143:265-272.

10. Guo Q, Ghadiri R, Weigel T, Aumann A, Gurevich EL, Esen C, et al. Comparison of In Situ and Ex Situ Methods for Synthesis of Two-Photon Polymerization Polymer Nanocomposites. Polymers. 2014;6(7):2037-2050.

11. Delogu F, Gorrasi G, Sorrentino A. Fabrication of polymer nanocomposites via ball milling: Present status and future perspectives. Progress in Materials Science. 2017;86:75-126.

12. Prakash S, Kumar S. Experimental investigations and analytical modeling of multi-pass $\mathrm{CO}_{2}$ laser processing on PMMA. Precision Engineering. 2017;49:220-234.

13. Shokr FS. Evaluation of the optical properties of photoconductive Eosin/PMMA nanocomposite film for flexible optoelectronic applications. Optik - International Journal for Light and Electron Optics. 2017;149:270-276.

14. Junior WS, Emmler T, Abetz C, Handge UA, Santos JF, Amancio-Filho ST, et al. Friction spot welding of PMMA with PMMA/silica and PMMA/silica-g-PMMA nanocomposites functionalized via ATRP. Polymer. 2014;55(20):5146-5159.

15. Vivaldo I, Moreno M, Torres A, Ambrosio R, Rosales P, Carlos $\mathrm{N}$, et al. A comparative study of amorphous silicon carbide and silicon rich oxide for light emission applications. Journal of Luminescence. 2017;190:215-220.

16. Majid A. A perspective on non-stoichiometry in silicon carbide. Ceramics International. 2018;44(2):1277-1283. DOI: http:// dx.doi.org/10.1016/j.ceramint.2017.10.165

17. Zeller F, Müller C, Miranzo P, Belmonte M. Exceptional micromachining performance of silicon carbide ceramics by adding graphene nanoplatelets. Journal of the European Ceramic Society. 2017;37(12):3813-3821.

18. Araújo SC, Kawano Y. Espectro Vibracional no Infravermelho Próximo dos Polímeros Poliestireno, Poli(Metacrilato e Metila) e Policarbonato. Polímeros. 2001;11(4):213-221.

19. Ji X, Hao H, Wu Q, Zhu B, Sun F. Surface modification of silicon carbide powders with aminoorganosilanes. Journal of Wuhan University of Technology-Materials Science Edition. 2007;22(4):754-756.

20. Rêgo JKMA, Nascimento JHO, Agrawal P, Mélo TJA, Costa $\mathrm{MCB}$, Ito EN. Influence of amine groups in the chemical structure of photochromic dyes on the rheological and mechanical properties of poly(methyl methacrylate) (PMMA). Dyes and Pigments. 2017;142:350-357.

21. Liu D, Li W, Zhang N, Huang T, Yang J, Wang Y. Graphite oxide-driven miscibility in PVDF/PMMA blends: Assessment through dynamic rheology method. European Polymer Journal. 2017;96:232-247.

22. Holland BJ, Hay JN. The kinetics and mechanisms of the thermal degradation of poly(methyl methacrylate) studied by thermal analysis-Fourier transform infrared spectroscopy. Polymer. 2001;42(11):4825-4835. 
23. Džunuzović E, Jeremić K, Nedeljković JM. In situ radical polymerization of methyl methacrylate in a solution of surface modified $\mathrm{TiO}_{2}$ and nanoparticles. European Polymer Journal. 2007;43(9):3719-3726.
24. Kashiwagi T, Inaba A, Brown JE, Hatada K, Kitayama T, Masuda E. Effects of weak linkages on the thermal and oxidative degradation of poly(methyl methacrylates). Macromolecules. 1986;19(8):2160-2168. 